\title{
O ENSINO COM A PRÁTICA DA PESQUISA: DELINEAMENTO DE UMA NOVA PROPOSTA DE FORMAÇÃO
}

Mara Eliane Fonseca RODRIGUES 1

Esther Hermes LÜCK2

Vera Lúcia Alves BREGLIA ${ }^{3}$

\section{RESUMO}

Discute a necessidade de introduzir uma nova concepção de ensinar e aprender na universidade, pautada pela articulação entre ensino e pesquisa. Considera que essa concepção pode ser viabilizada no âmbito do ensino de Biblioteconomia e Ciência da Informação. Para tanto, apresenta uma nova proposta de formação para o profissional da informação.

Palavras-chave: Articulação Ensino e Pesquisa; Ensino de Ciência da Informação.

\begin{abstract}
The paper presents perspectives to integrate research practices in Information Science undergraduate education.
\end{abstract}

Key words: Research and Education; Information Science Education.

\section{PREÂMBULO}

Primeiramente, quero manifestar minha satisfação em fazer parte deste Painel, onde pretende-se discutir a pesquisa discente nos cursos de graduação de Biblioteconomia e Ciência da Informação. A satisfação aumenta ao constatar que meus companheiros de discussão e de reflexão são colegas que formam o que denomino de "coletivo qualificado", isto é, pessoas realmente comprometidas em buscar a educação em sua plenitude, para quem ensino e a pesquisa são meios de despertar a criati- vidade e o espírito crítico e, assim, propiciar os conhe- cimentos necessários à transformação social.

As reflexões que trago para compartilhar com este coletivo, sobre tão importante tema, não são somente minhas. São fruto de um trabalho conjunto, desenvolvido ao longo dos últimos anos com as professoras Esther Hermes Lück e Vera Lúcia Alves Breglia, ambas docentes do Departamento de Ciência da Informação da Universidade Federal Fluminense, do qual também faço parte.

\footnotetext{
1. Professora do Departamento de Ciência da Informação - UFF e Mestre em Ciência da Informação pela UFRJ/IBICT. Assessora da Pró-Reitoria de Assuntos Acadêmicos. e-mail: mara@proac.uff.br

2. Professora do Departamento de Ciência da Informação - UFF e Mestre em Ciência da Informação pela UFRJ/IBICT. Pró-Reitora de Assuntos Acadêmicos. e-mail: luck@proac.uff.br

3. Professora do Departamento de Ciência da Informação - UFF e Mestre em Ciência da Informação pela UFRJ/IBICT. e-mail: vbreglia@domain.com.br
} 
Com a primeira, tenho vivenciado os debates que envolvem as alterações que deverão ser introduzidas na estrutura e organização dos currículos dos cursos de graduação devido os ditames estabelecidos pela Nova Lei de Diretrizes e Bases da Educação Nacional - LDB (Lei n 9394, de 20/12/1996) e demais instruções do MEC e CNE acerca do ensino de graduação. A possibilidade de vivenciar este momento,acontece por que a profa. Esther, além de fazer parte do quadro docente do Departamento, atualmente responde pela Pró-Reitoria de Assuntos Acadêmicos, instância responsável pela formulação e acompanhamento da política de ensino de graduação da Universidade. Na qualidade de PróReitora, a referida professora convidou-me a integrar sua equipe para auxiliar na condução deste trabalho.

Com a professora Vera Lúcia tenho vivido os problemas estruturais do ensino de Biblioteconomia e Ciência da Informação, que ecoam na sala de aula: temos compartilhado as dificuldades, as dúvidas, as angústias que se impõem ao exercício da docência frente a um tempo de rápidas, constantes e profundas mudanças. Mediante esse contexto tão conturbado, sentimos a necessidade de buscar um suporte didádico-pedagógico que permita trabalhar o conhecimento buscando conexões e interações. Desse modo, tentamos fazer da sala de aula um espaço privilegiado de diálogo e práticas que conduzam os alunos à produção de um pensamento ao mesmo tempo múltiplo, individualizado, consciente e libertário.

Os esforços até então realizados, no sentido de buscar um modelo de formação que atenda aos desafios do futuro tendo como referência, de forma geral, as demandas que a sociedade impõe à universidade e em um plano mais específico à formação do profissional da informação, estão relatados em dois textos produzidos recentemente em colaboração com as referidas professoras (RODRIGUES e LÜCK, 2001; BREGLIA e RODRIGUES, 2001). As reflexões e as propostas contidas nestes textos servem de base para a exposição que ora apresento; por esse motivo considero as professoras mencionadas co-autoras desta apresentação.

\section{A UNIVERSIDADE FRENTE AOS DESAFIOS DO SEU TEMPO}

Tradicionalmente, a Universidade sempre foi reconhecida como local onde se pensa de forma crítica. A consequiência natural é o estabelecimento de trocas: produz-se conhecimento, dissemina-se informação, mas sem esquecer a realimentação dessas trocas, ou seja, a indispensável interação com a sociedade.

Para Santos (1995), a Universidade hoje encontra-se duplamente desafiada pela sociedade e pelo Estado sem, contudo, estar preparada para enfrentá-los, uma vez que a demanda é por transformações profundas e não por simples reformas parcelares.

Em especial, para a universidade brasileira, as contradições fazem parte de sua história. Com relação ao modelo, à idéia de universidade, desde a sua gênese, ela vem enfrentado dificuldades que se prendem a inúmeros fatores. Um dos autores que referenda essa afirmativa é Nagle (1987), para quem o padrão brasileiro de escola superior nasceu acomodado a interesses sociais das velhas elites. Esse modelo guardava fortes marcas de autosuficiência, especialização e tradicionalismo, além de estar adaptado a uma visão conservadora do mundo, e preservou sua função primeira de preparação de profissionais liberais.

Contudo, o processo contínuo de mudanças que ocorre na sociedade contemporânea, e que atinge a realidade brasileira, leva a Universidade a refletir sobre seu papel educativo-formador. A pluralidade de destrezas que a vida atual requer e a multiplicidade de informações que se tornam disponiveis com as novas tecnologias, são fortes fatores de pressão sobre as verdades inquestionáveis sedimentadas na prática curricular e pedagógica da Universidade. O paradigma de ensinar e aprender até agora dominante, baseado em um enfoque epis- 
temológico disciplinar, carece, portanto, da exploração de outras alternativas.

A Universidade Federal Fluminense - UFF, como as demais universidades brasileiras, sofre os desafios do seu tempo. Nesse momento, se avizinham profundas mudanças nas estruturas curriculares das universidades brasileiras, conseqüência da regulamentação da Nova LDB. Esta lei revogou toda a legislação em que se baseou a formulação dos atuais currículos dos cursos superiores no Brasil; preconiza o princípio da flexibilidade curricular (permitir ao aluno utilizar os conteúdos curriculares de acordo com suas potencialidades, levando em conta os conhecimentos prévios adquiridos em sua experiência de vida) e assegura a competência da Universidade de fixar os currículos dos seus cursos, desde que observadas as diretrizes pertinentes.

Diante dessa nova exigência, a Universidade Federal Fluminense, na crença da necessidade de promover e aprofundar as discussões em torno da proposição de um novo modelo de estrutura curricular para a Universidade, iniciou um trabalho no sentido de buscar a definição de uma ação efetiva de mudança. Através da Pró-Reitoria de Assuntos Acadêmicos, vem desenvolvendo uma série de ações que visam criar condições para a reorganização curricular dos Cursos de Graduação, de acordo com os parâmetros estabelecidos pela LDB. Nesse sentido, em uma primeira etapa, procurou balizar seu trabalho tanto através de estudos similares ocorridos em outras universidades, como pelo exame de material bibliográfico produzido em outras esferas (Ministério da Educação, Unesco, Fórum de Pró-Reitores de Graduação das Universidades Brasileiras).

O Fórum de Pró-Reitores de Graduação das Universidades Brasileiras - ForGRAD, desde sua criação em 1988, tem se preocupado em congregar as universidades em torno de iniciativas que permitam o fortalecimento de ações comuns relativas ao ensino de graduação. Desse modo, construiu, a partir de reflexões, críticas e sugestões discutidas em seus encontros regionais, um Plano Nacional de Graduação que constitui-se em um dos instrumentos referenciais para as ações político-acadêmicas das universidades brasileiras. (ForGRAD, 1999)

Tendo este documento como referência partiu-se, em um segundo momento, para a análise do texto da Lei de Diretrizes e Bases e discussão da legislação complementar originada do Ministério da Educação, observando-se também as tendências de mudanças para o ensino superior em nível mundial, anunciadas pela Unesco. (BRASIL. MEC, 1997; CONFERÊNCIA MUNDIAL SOBRE O ENSINO SUPERIOR,1999)

Esta etapa foi realizada em conjunto com o Fórum de Coordenadores dos Cursos de Graduação, instância que congrega os professores responsáveis pelo acompanhamento da implementação dos projetos pedagógicos dos cursos. À luz da análise empreendida, a próxima etapa foi constituir, no âmbito do referido Fórum, grupos de trabalho para estudar e sugerir uma política de graduação para a Universidade. O resultado do trabalho de cada grupo foi apresentado e discutido em reuniões plenárias do Fórum, sistematizadas e consolidadas em um documento único, intitulado: Diretrizes para a Política de Graduação na UFF. (UFF, 1999)

É importante ressaltar que durante a realização desta última etapa, os grupos se preocuparam em observar, discutir/analisar as condições em que vem se realizando a prática universitária o que permitiu compreender a necessidade de intervir nos currículos dos cursos de graduação. Observada a organização curricular vigente na Universidade, percebeu-se que os currículos dos cursos ainda se norteiam pela influência da concepção positivista de construção do conhecimento. $\mathrm{O}$ conhecimento é organizado de uma forma linear - do geral para o particular, do teórico para o prático, do ciclo básico para o profissionalizante - fazendo com que as experiências de ensino sejam vivenciadas isoladamente, de forma particularizada. Desse modo, as experiências se perdem no isolamento das especialidades.

Diante de um tempo que exige o encontro, a convivência e a troca permanente de informações 
como forma de potencializar novas experiências no processo de formação, não se pode ignorar que o atual modelo organizacional (compartimentalizado) em que se assentam os cursos de graduação está um tanto quanto ossificado.

A partir da emergência de um novo paradigma unificador do pensamento e da ação humana procura-se vencer a fragmentação do conhecimento, gerada pelo paradigma cartesiano. O que está em debate, portanto, é a necessidade da busca de sentido para o ensino contemporâneo, numa perspectiva não fragmentária.

A Universidade Federal Fluminense, a partir da construção coletiva do documento Diretrizes para a Política de Graduação na UFF, busca nortear suas ações em direção de uma política conseqüente para o ensino de graduação e pretende colocar-se em estreita sintonia com os desafios do seu tempo.

Tendo como referência esse cenário de mudanças e as ações até aqui implementadas pela Universidade, a seguir nos propomos a delinear o que pensamos ser uma proposta de formação inovadora.

\section{A PESQUISA COMO PRINCÍPIO DE UM PROGRAMA DE FORMAÇÃO}

O traçado do caminho vai ao encontro das mudanças previstas para a universidade brasileira, pois entendemos que o momento atual é vital para que se possa estabelecer uma reformulação efetiva nos parâmetros que tem orientado a educação superior no Brasil e, em particular, o ensino de Biblioteconomia e Ciência da Informação, uma vez que a LDB apresenta características bastante novas para a estrutura e funcionamento do ensino universitário.

A questão que surge a partir da instituição da norma é como fazer a ruptura dentro dela, ou seja, como trabalhar uma nova concepção de ensino e de aprendizagem em uma estrutura tão rigidamente construída e sedimentada como é a da universidade. É necessário que além de reformulações estruturais, as mudanças sejam conceituais; a nova maneira de pensar e produzir o conhecimento vai implicar na utilização de referências, conteúdos, valores simbólicos, expressão de culturas, ou seja, "competências cognitivas influenciadas por vivências do passadoe pelas expectativas do futuro, sem jamais ser possivel conceber um começo ou um fim absolutos" (BARRETO, 1994).

Entendemos que a concepção de ensino que tem na pesquisa seu elemento constituidor contrapõe-se às práticas baseadas na visão positivista de construção do conhecimento, na qual os conteúdos ficam fracionados, descontextualizados, desproblematizados, resultando no aprendizado memorístico. Morin (2000) ao discutir a disciplinaridade do conhecimento, indaga:

“... de que nos serviriam todos os saberes parcelados, se nós não os confrontássemos, a fim de formar uma configuração que responda às nossas expectativas, às nossas necessidades e às nossas interrogações cognitivas?"

A idéia do ensino articulado à pesquisa baseia-se em atitudes analíticas, reflexivas, questionadoras e problematizadoras, em que a aprendizagem parte das observações próprias para indagar sobre o conhecimento e o próprio mundo. Assim, nessa metodologia de ensino, adota-se como referência o ato de interrogar, (re)produzir e criar: interrogar a realidade de modo crítico e permanente, (re)produzir o conhecimento de modo consciente de suas limitações e orientar o aluno para a busca de soluções criativas para os problemas com que se defronta. (ForGRAD, 2000)

As ações nessa direção terão que passar por uma modificação na relação professor-aluno tradicionalmente instituída na universidade em que o aluno é visto apenas como reprodutor do conhecimento. A perspectiva de trabalhar o ensino articulado à pesquisa, recoloca o papel do professor definindo-o "como orientador do processo de questionamento [re]construtivo no aluno" (DEMO, 1997). O ensino com pesquisa envolve "estudantes e professores numa 
criação de conhecimento comumente partilhado como intuito de que a realidade seja apreendida e não somente reproduzida" (CUNHA, 1997). Assim, é importante estimular um trabalho de criação coletiva em que o professor e o aluno se incluam como autores, desenvolvendo a capacidade de negociar, articular e ser solidário. Essa exigência está para além da construção de um novo paradigma de ensinar e aprender na universidade, onde o aluno não é apenas um sujeito contemplativo da realidade, mas sim envolvido com ela. Em outras palavras, o aluno deixa de ser objeto do ensino e passa a ser sujeito do processo. Fundamentalmente, é necessário que nesse processo, seja revisto o conceito de pesquisar, considerando-o como uma atitude investigativa a ser formada.

A atribuição do mesmo grau de importância ao ensino e à pesquisa passa, portanto, por uma revisão didática, pela investigação de novas formas de transmitir e produzir conhecimento no processo de formação na graduação, o que seria dizer que também faz-ze necessário identificar de que instrumentos metodológicos a universidade dispõe e pode colocar em prática.

Não se deve esquecer que todo exercício profissional se dá em um tempo e um lugar determinados, em estreita relação com projetos que podem fechar ou abrir os horizontes humanos. Todo o saber é contextualizado historicamente, assim como toda atividade profissional humana se dá em contexto social, portanto, a aquisição de conhecimentos deve ir além da aplicação imediata e impulsionar o sujeito, em sua dimensão individual e social, a criar e responder a desafios.

A formação universitária deve pautar-se, portanto, pelo espírito de investigação. A universidade deve fazer da pesquisa parte do programa curricular dos cursos e formar profissionais com capacidade de investigar/buscar solução para os mais variados problemas.

A associação do ensino com pesquisa na graduação pode ser pensada pela via da construção do conhecimento que se faça de forma conjunta por professores e alunos, a partir dos conhecimentos que possuam, com respeito às suas experiências como sujeitos da história dentro e fora da escola (ANDRÉ, 1994). O investimento nos saberes de que são portadores faz de ambos sujeitos do diálogo, dispostos à interlocução, o que conduz a ver, fazer e agir diferente. Também possibilita uma ausência da "hierarquização" presente na relação professor/ aluno; dá nova forma ao espaço/tempo. Essa modalidade de relação produz "auditórios" de falantes/ouvintes e de ouvintes/falantes, espaço privilegiado de fluição (e por que não fruição?) de idéias, reunião de diferenças, resemantização de repertórios, clima ideal para viver e "com-viver".

\section{O PRESENTE NO FUTURO: A PESQUISA EM SALA DE AULA}

As questões anteriormente colocadas configuram a sala de aula como espaço-síntese, não só porque recebe o eco das novas idéias, mas porque tem o compromisso de operacionalizá-las.

Faz-se necessário portanto, romper o "engessamento" que muitas vezes travestido em rigor, obstrui o diálogo na sala de aula, e impõe aos alunos uma atitude passiva, de ouvintes. A passagem dos ouvintes a falantes/ouvintes se faz por uma valorização dos saberes que os alunos detém, entendidos como parte importante de repertórios próprios, reflexo de pertencimento a diferentes grupos e comunidades.

No nosso entender seria essa a substância de um trabalho que pretende formar profissionaiscidadãos, conscientes, atuantes. Imaginamos que o resultado iria de encontro a comportamentos tão recorrentes quanto reducionistas: o uso abusivo, magicizado e banalizado das categorias cidadão $e$ cidadania, que descontextualizadas esvaziam-se de sentido. O sentir-se cidadão e a possibilidade do exercício da cidadania passam pelo merecimento, pelo respeito, pela valorização dos indivíduos, pela possibilidade de serem partícipes na tomada de decisões. 
Daí ser fundamental levar em conta a profusão de falas, manifestações e seus múltiplos significados, terreno propício a se estabelecerem relações dialógicas, o que resulta na adoção de uma abordagem pedagógica inclusiva. Isso só vai ser possível a partir da aceitação de que "o contexto universitário, embora baseado em certas normas amplas de tolerância e comunicação aberta, não está de forma alguma isento de restrições" (BURBULES e RICE, 1993). É justamente por aí que tem sido encaminhado o trabalho que vem sendo por nós desenvolvido; atenção não somente às diferenças mas, sobretudo, às possíveis restrições que daí advenham, especialmente as de caráter estrutural. A necessidade de moldar estratégias que evitem a paralisação, tem sido trabalhada através da auto estima. Têm sido insistentemente demonstradas aos alunos as diferentes possibilidades de leitura, que perpassem a simples decodificação de símbolos, e possibilitem o adentramento aos textos que se traduz em leitura interpretativa. Também têm sido valorizados os repertórios de cada um, como representantes de universos particulares.

$\mathrm{Na}$ prática, a metodologia está baseada na leitura/análise de textos. Há sempre um textoreferência que dá sustentação aos outros textos que compõem o eixo temático em estudo. $\mathrm{O}$ resultado dessas leituras é trazido à sala de aula para discussão. Há um estímulo para que os alunos se coloquem e permitam que suas experiências e suas vivências integrem o que denominamos leitura intertextual. Esse é um primeiro momento da estratégia de ensino adotada; o seu resultado prevê a assimilação de conceitos básicos, identificação dos problemas abordados pelos textos e um posicionamento crítico frente às questões discutidas.

Em um segundo momento, a estratégia se apoia no referencial teórico anteriormente trabalhado. A concretização dessa etapa se dá a partir de uma atitude investigativa, que permite lançar um olhar crítico às ações praticadas em ambientes informacionais. Nessa fase do trabalho a investigação/pesquisa não é considerada somente como um princípio científico - busca de conhecimento ou simples descoberta que termina na análise teórica - mas principalmente como um princípio educativo - forma natural de estabelecer o diálogo com a realidade que leva o aluno a despertar a sensibilidade, ser capaz de fazer uma leitura de mundo e desenvolver a capacidade de investigar/ buscar soluções para os mais variados problemas.

As idéias que serviram de motivação ao trabalho visavam superar algumas dificuldades trazidas pelos alunos, produto dos sistemas de ensino por eles vivenciado. Assumimos o desafio de fazer a contramão do processo e levá-los a ocupar o lugar que lhes cabe, de sujeitos pensantes. $\mathrm{O}$ trabalho ainda se encontra em estágio de maturação e não se propõe primordialmente a formar pesquisadores, mas a criar nos alunos uma predisposição ao gosto pela pesquisa.

A decisão de deslocar o futuro para o presente possibilita lidar com os problemas estruturais do ensino de Biblioteconomia e Ciência da Informação, que tem levado à formação de profissionais considerados mais de nível técnico do que científico ou trabalhadores intelectuais. De outro lado, acreditamos estar preparando os alunos para vivenciarem as mudanças em curso na universidade brasileira.

Finalmente, gostaríamos de ressaltar que acreditamos ser possível construir uma proposta pedagógica diferenciada daquela em que fomos formados. Contudo, este esforço não pressupõe iniciativas isoladas, pois trata-se de um exercício coletivo.

A resignificação do ato de ensinar e aprender na universidade impõe, portanto, esse esforço coletivo. Este movimento é também necessário no âmbito do ensino de Biblioteconomia e Ciência da Informação pois, para que se busque formar profissionais com perfis diferenciados a fim de responder as exigências de uma sociedade em transformação, é preciso, antes de tudo, que novas posturas diante do ato de ensinar e aprender sejam efetivamente assumidas. 


\section{REFERÊNCIAS BILIOGRÁFICAS}

ANDRÉ, Marli E.D. A Formação de professores em serviço: um diálogo com vários textos. Cadernos de Pesquisa, São Paulo, n. 89, pp. 72-75, maio, 1994.

BARRETO, Aldo de A. A questão da informação. São Paulo em Perspectiva, São Paulo, v. 8, n. 4, pp. 3-8, 1994.

BRASIL. Lei de Diretrizes e Bases da Educação Nacional, de 20 de dezembro de 1996. Estabelece as diretrizes e bases da educação nacional.

BRASIL. MEC. Conselho Nacional de Educação. Parecer $n^{0}$ 776/97. Orientação para as diretrizes curriculares dos cursos de graduação. [Brasília, 1997]

BREGLIA, Vera Lúcia A.; RODRIGUES, Mara Eliane F. O Desafio de modelar a formação profissional: o futuro no presente. In: CONGRESSO NACIONAL BAD, 7., 2001, Porto. Actas... Porto: BAD, 2001. 1 CD-ROM.

BURBULES, Nicholas C. e RICE, Suzanne. Diálogo entre as diferenças: continuando a conversação. In: SILVA, Tomaz Tadeu da. Teoria educacional crítica em tempos pós-modernos. Porto Alegre: Artes Médicas, 1993. pp. 173-204.

CONFERENCIA MUNDIAL SOBRE O ENSINO SUPERIOR (1998: Paris, França). Tendências da
Educação Superior para o Século XXI. Brasília: UNESCO/CRUB, 1999.

CUNHA, Maria Isabel. O Currículo do ensino superior e a construção do conhecimento. In: FÓRUM NACIONAL DE PRÓ-REITORES DE GRADUAÇÃO. Memória. [Campinas] 1997. pp. 181-185.

DEMO, Pedro. Educar pela pesquisa. 2. ed., Campinas: Autores Associados, 1997. 120 p.

ForGRAD. Plano Nacional de Graduação. [Ilhéus] 1999.

ForGRAD. O Currículo como Expressão do Projeto Pedagógico: um processo flexível. Niterói, 2000.

MORIN, Edgar. Articular os saberes. In: ALVES, Nilda; GARCIA, Regina L. (org.). O Sentido da Escola. 2. ed., Rio de Janeiro: DP\&A, 2000. pp. 65-80.

NAGLE, Jorge. A educação na virada do século. Ci ência e Cultura., Rio de Janeiro, v. 39, n. 3, pp. 287-291, mar. 1987.

RODRIGUES, Mara Eliane F.; LÜCK, Esther Hermes. A Resignificação do ato de ensinar e aprender na universidade: o ensino de Biblioteconomia em questão. In: CONGRESSO NACIONAL BAD, 7, 2001, Porto. Actas... Porto: BAD, 2001. 1 CD-ROM.

UFF. Pró-Reitoria de Assuntos Acadêmicos. Fórum de Coordenadores para os Cursos de Graduação. Diretrizes para a política de Graduação na UFF. Niterói, 1999. 